University of Nebraska - Lincoln

DigitalCommons@University of Nebraska - Lincoln

Nutrition and Health Sciences -- Faculty

Publications

Nutrition and Health Sciences, Department of

$4-2011$

\title{
Content Validation of a Standardized Language Diagnosis by Certified Specialists in Gerontological Nutrition
}

\author{
Paula K. Ritter-Gooder \\ University of Nebraska-Lincoln, pgooder@windstream.net \\ Nancy M. Lewis \\ University of Nebraska--Lincoln, nlewis2@unl.edu \\ Kent M. Eskridge \\ University of Nebraska - Lincoln, keskridge1@unl.edu
}

Follow this and additional works at: https://digitalcommons.unl.edu/nutritionfacpub

Part of the Dietetics and Clinical Nutrition Commons

Ritter-Gooder, Paula K.; Lewis, Nancy M.; and Eskridge, Kent M., "Content Validation of a Standardized Language Diagnosis by Certified Specialists in Gerontological Nutrition" (2011). Nutrition and Health Sciences -- Faculty Publications. 6.

https://digitalcommons.unl.edu/nutritionfacpub/6

This Article is brought to you for free and open access by the Nutrition and Health Sciences, Department of at DigitalCommons@University of Nebraska - Lincoln. It has been accepted for inclusion in Nutrition and Health Sciences - Faculty Publications by an authorized administrator of DigitalCommons@University of Nebraska - Lincoln. 


\title{
Content Validation of a Standardized Language Diagnosis by Certified Specialists in Gerontological Nutrition
}

\author{
Paula K. Ritter-Gooder, PhD, RD, CSG, LMNT, Department of Nutrition and Health Sciences, University of Nebraska-Lincoln \\ Nancy M. Lewis, PhD, RD, FADA, Department of Nutrition and Health Sciences, University of Nebraska-Lincoln \\ Kent M. Eskridge, PhD, Department of Statistics, University of Nebraska-Lincoln
}

Corresponding author - P. K. Ritter-Gooder, Department of Nutrition and Health Sciences, 312 RLH, University of Nebraska-Lincoln, Lincoln, NE 68583-0806; email pgooder@windstream.net

\begin{abstract}
Validation of the nutrition standardized language assures the language is accurate for use in practice, policy, and research, but few validation studies have been reported. The purpose of this descriptive study was to validate content of all components of the nutrition diagnostic term involuntary weight loss using experts providing care for older adults in health care settings. A Nutrition Diagnosis Validation Instrument was developed that contained the definition, etiologies, and signs and symptoms of the diagnosis plus items added from literature review. Questions on clarity and completeness of the language were included. The Nutrition Diagnosis Validation Instrument used a Likert-type scale for deriving a Diagnostic Content Validity (DCV) score for all items in the definition, etiology, and signs and symptoms components to define major, minor, and nonrelevant characteristics and a mean total DCV score for the term. In 2008, all Board Certified Specialists in Gerontological Nutrition (CSGs) were recruited by mail. CSGs ( $n=110,73 \%$ response) reported $15 \pm 10$ (mean \pm standard deviation) practice years in gerontological nutrition. The total DCV component scores were $0.80 \pm 0.17$ (definition), $0.63 \pm 0.08$ (etiology), and $0.69 \pm 0.12$ (signs and symptoms). The mean total DCV score of the diagnostic term was $0.69 \pm 0.11$. Cognitive decline, poor oral health, and impaired skin integrity were identified as missing language. In conclusion, the majority of the definition, etiologies, and signs and symptoms of the term were contentvalidated, including seven items derived from literature review. The validated items, including recommendations for added language, need to be retested using the same process.
\end{abstract}

The American Dietetic Association's (ADA) 2003 introduction of the Nutrition Care Process/Standardized Language $(\mathrm{NCP} / \mathrm{SL})$ provided dietetics practitioners with a model for quality care and a taxonomy describing the unique services of dietetics practitioners (1$4)$. The use of SL, published in the International Dietetics and Nutrition Terminology (IDNT) Reference Manual (5), in electronic and personal health records will enable patients, caregivers, and providers to prevent or manage acute and chronic disease $(6,7)$. Nutrition diagnoses were the first SL terms identified. Validation, the next step in language development, produces evidence that the diagnostic terms exist, and that their definitions, etiologies, and signs and symptoms are appropriate. Validation refines the SL for use in education, practice, research, and policy. Research models for validation of nursing diagnoses have been used since 1983 and have applicability for validating SL used in the NCP (8-12).

Few validation studies of the SL have been conducted. In one study, the content validity of all nutrition diagnostic terms was measured using a convenience sample of registered dietitians (RDs) (13). A reliability study of the use of the terms among RDs at different practice levels has been reported (14). Validation studies are needed utilizing experts who provide nutrition care for nutrition diagnoses among all practice settings and patient populations.

One IDNT diagnostic term, involuntary weight loss, occurs in many patient populations and practice settings. It is prevalent in up to $65 \%$ of long-term care residents who experience malnutrition (15). The prevalence of weight loss is the highest-ranked quality measure of nutrition/eating established by the Centers for Medicaid and Medicare for long-term care facilities receiving federal funding $(16,17)$. Weight loss has been sufficiently validated to qualify as an indicator of nursing home quality and each facility's report is publicly available (18). Failure to diagnose and treat unintended weight loss leads to increased risk for patient mortality and potential for litigation (19). Dietetics practitioners, including Board-Certified Specialists in Gerontological Nutrition (CSG) (20), identify and treat this nutrition problem in elderly people with outcomes of increased energy, protein, and nutrient intake, weight gain, and improved quality of life (21-26).

IDNT diagnostic terms are comprised of three com- 


\section{NUTRITION DIAGNOSIS VALIDATION INSTRUMENT (NDVI)}

INSTRUCTIONS: Indicate how prevalent or common this definition, etiology, sign or symptom is when this diagnosis or nutrition problem is present. Rate the definition, etiology, and each sign and symptom in the boxes to the right of the item by marking the box which agrees with your opinion. Please mark only one box for each item.

\begin{tabular}{|c|c|c|c|c|c|c|}
\hline Nutrition Diagnostic Term NC-3.2 Involuntary Weight Loss & 总章 & 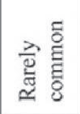 & 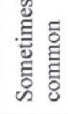 & 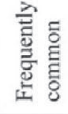 & 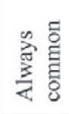 & 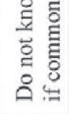 \\
\hline \multicolumn{7}{|l|}{ 1. Definition: Decrease in body weight that is not planned or desired. } \\
\hline \multicolumn{7}{|c|}{$\begin{array}{l}\text { 2. Etiology: (Cause/Contributing Factors) Factors gathered during the nutrition assessment process that contribute to the existence or the maintenance of } \\
\text { pathophysiological, psychosocial, situational, developmental, cultural, and/or environmental problems. }\end{array}$} \\
\hline a) Prolonged catabolic illness & & & & & & \\
\hline b) Trauma & & & & & & \\
\hline c) Malabsorption & & & & & & \\
\hline d) Lack of or limited access to food & & & & & & \\
\hline e) Economic constraints & & & & & & \\
\hline f) Restricting food given to elderly and/or children & & & & & & \\
\hline
\end{tabular}

Figure 1. Nutrition Diagnosis Validation Instrument sample.

ponents; definition, etiology, and signs and symptoms. Validating content of all components of the diagnostic term involuntary weight loss within the older adult population using experts providing care for this problem refines the term for future use. The purpose of this study was to measure the content validity of the nutrition diagnostic term NC-3.2 Involuntary Weight Loss (5) in elderly people using CSGs as experts.

\section{Methods}

\section{Concept Analysis}

Content validation of a diagnostic term gathers evidence that RDs identify common definition, etiologies, and signs and symptoms, that language items are relevant and represent the nutrition problem, and that signs and symptoms occur as a cluster in a sufficient number of cases (27). Before validation, the term is analyzed using concept analysis, a study of the attributes or characteristics of the term (28-30). A literature review was conducted using the words involuntary weight loss, undesirable weight loss, and elderly to identify whether additional items need to be added to the IDNT term for testing. Four etiologies and seven signs and symptoms were added to the term.

\section{Validation Instrument}

A Nutrition Diagnosis Validation Instrument (NDVI) (Figure) was developed based upon the Fehring Diagnostic Content Validity Model $(8,13)$. The model, used in nursing diagnosis research, obtains quantifiable data using weighted inter-rater reliability ratios, provides a standardized approach for comparison studies, and establishes criteria for decisions about the credibility of the defining characteristics. The NDVI listed all components (definition, etiologies, and signs and symptoms) of the published term (5), plus those added from litera- ture review. All etiologies and signs and symptoms were listed separately to collect a rating for each item $(n=51)$. To provide clarity, items such as "poor intake" and "fever" were defined (31). The NDVI used a 5-point Likerttype scale, plus a "do not know" response for rating how common or characteristic each item is when involuntary weight loss is present in a patient. Response options for the signs and symptoms were: not at all characteristic $=1$, very little characteristic $=2$, somewhat characteristic $=3$, considerably characteristic $=4$, very characteristic $=5$, and do not know if characteristic. Other questions asked whether additional language was needed for the definition, etiologies, and signs and symptoms and whether the language was clear and easy to understand. If wording was missing or unclear, an explanation was requested. Final questions inquired whether the diagnostic term was used in practice and, if not, reasons for any nonuse of the term. A 17-item demographic and practice questionnaire was included in the study. After approval was obtained for the study from the Institutional Review Board, the NDVI and demographic questionnaire were reviewed by two members of ADA's NCP/SL Committee and minor adjustments were made to improve clarity.

\section{Expert Raters}

To provide scientific rigor, experts were used for validating content of the term. CSGs, recognized for their expertise and skills in gerontological nutrition by their professional peers, were identified as experts in the diagnostic term in older adults, using the expert scale rating proposed by Fehring (9). A Commission on Dietetic Registration mailing list of CSGs was used to select six CSGs to pilot test the NDVI and demographic questionnaire. After modifying instruments to improve clarity and minimize response error, all CSGs $(n=151)$ were invited to participate by mail using up to five contacts (32). Voluntary participation was implied when the NDVI and demographic questionnaire were completed and returned. 


\section{Data Analysis}

Data were analyzed with SPSS for Windows (version 16.0, November, 2007, Chicago, IL). A Diagnostic Content Validity (DCV) score was calculated using the Likert scale ratings: $1=0,2=0.25,3=0.50,4=0.75$, and $5=1.0$ to derive a weighted mean for each item in the term (9). Items with DCV scores of $\geq 0.80$ were classified as major characteristics, 0.50 to 0.79 were minor characteristics, and those scoring $<0.50$ were nonrelevant to the diagnosis. After item DCV scores were obtained, a mean total DCV score for each component (definition, etiology, and signs and symptoms) of the term was calculated using all DCV scores of the major and minor characteristics within that component. Using these component total DCV scores, a mean total DCV score of the entire term was derived. The "do not know responses" were summarized as frequencies and percentages and were not computed into the DCV score. Comments regarding missing language were analyzed for common themes. The demographic and practice questions were summarized using frequencies, percentages, and means with standard deviations.

Each participant was assigned an expert scale rating using the following point system; master's degree $=$ 2, published articles on the diagnosis $=2$, current clinical practice of at least 1 year duration in area relevant to the diagnosis $=1$, and certification in an area of clinical practice relevant to the diagnosis of interest $=2(9)$. The Total DCV diagnostic term scores within subgroups of CSGs by expert scale rating, years of practice in gerontological nutrition, and usage of the NCP/SL were compared.

\section{Results and Discussion}

SL has been proposed for use in dietetics practice, but few studies have validated the language. The intent of this study was to validate the content of the SL diagnostic term involuntary weight loss among experts providing nutrition care for this problem within the older population, and learn whether the language is clear and complete.

Eighty-three percent of the CSGs responded to the mailing and $73 \%(n=110)$ participated. Thirty-nine percent practiced in the Midwest, $25 \%$ in the South, $22 \%$ in the Northeast, and $14 \%$ in the Western regions of the United States. Average number of years in gerontological nutrition practice was $15 \pm 10$ (mean \pm standard deviation). Eighty percent of the CSGs worked in long-term, skilled, and rehabilitation care. The average number of patients seen each month with involuntary weight loss was $19 \pm 23$. Fifty percent of the RDs currently use the $\mathrm{NCP} / \mathrm{SL}$ and of these, $54 \%$ have been in practice more than 20 years. Expert scale rating of the CSGs was 4.36 \pm 1.6 , indicating that raters were experts in the term. When RDs did not use the diagnosis, the most common reason given was that the SL had not been implemented in their practice.

\section{Validated and Nonvalidated Language}

A DCV score is a measure of how representative the language item is to the diagnosis and classifies the item as a major, minor, or nonrelevant characteristic. Higher scores, denoting major and minor characteristics, indicate more confidence that the item is present when the nutrition problem exists. The nonrelevant items have low DCV scores, do not represent the diagnostic term, and are not essential or needed cues to identify the nutrition problem. The Table lists DCV scores and major, minor, and nonrelevant classifications of all etiologies and signs and symptoms of the term.

The total DCV diagnostic term score, $0.69 \pm 0.11$, was similar across years in gerontology nutrition practice, expert scale rating, and use of NCP/SL. This score is lower than the 0.91 reported by Enrione (13) and is a reflection of the lower total DCV component scores found (definition $=0.80$ vs 0.99 , etiology $=0.63$ vs 0.92 , and signs and symptoms $=0.69$ vs 0.90 ). The current study surveyed experts in gerontological nutrition with experience in the diagnostic term, while Enrione (13) used a convenience sample of RDs to validate all the diagnostic terms. Experts use fewer cues compared to novices to arrive at correct diagnoses (33), and those in the current study rated $47 \%$ of the etiologies and $14 \%$ of the signs and symptoms as nonrelevant. Using experts for validation reduced the number of essential and necessary signs and symptoms in the term. This makes the language explicit and succinct for use with older adults, and lessens practitioner time required in deriving a nutrition diagnosis in the clinical setting (34). In addition, accurate diagnosing is made possible with valid and limited number of defining characteristics for the term (35). The degree of accuracy of a nutrition diagnosis can be measured by observing the number of validated signs and symptoms present in the patient state (36).

\section{Validated Language Additions}

Etiologies added from literature review, polypharmacy, high levels of emotional stress such as loss of loved one, and use of modified therapeutic diets were validated (Table). Increased amounts of medication taken are associated with poor nutritional status, and high levels of stress have an independent negative impact on energy intake $(25,37-42)$. Modified diets are often prescribed for the older adult, but liberalizing diet therapy based on current nutrition assessment and diagnosis is beneficial $(21,43-45)$. Older individuals on texture-modified diets were found to have a lower intake of energy and protein than those on normal diets (46-50). Loss of centrally distributed fat and client history of conditions associated with a diagnosis or treatment of gastrointestinal, kidney, and heart disease (51-53) were added signs and symptoms that were validated.

\section{Missing Language}

CSGs identified missing language in the term. The definition was rated by $78 \%$ of CSGs as complete, but $10 \%$ recommended "significant," "unavoidable," or "unintended" as added language. Eleven percent and 10\% of the CSGs, respectively, reported dementia/cognitive decline and poor oral health (difficulty chewing or poor dentition) as recommended language for the etiology 
Table 1. Diagnostic Content Validity (DCV) scores ${ }^{\mathrm{a}}$ of language items within components of the diagnostic term NC-3.2 Involuntary Weight Loss ${ }^{b}$ in older adults as rated by Board Certified Specialists in Gerontological Nutrition $(\mathrm{n}=110)$

\begin{tabular}{|c|c|}
\hline (mean \pm & $\begin{array}{l}\text { DCV score } \\
\text { deviation) }\end{array}$ \\
\hline \multirow{2}{*}{\multicolumn{2}{|c|}{$\begin{array}{l}\text { Definition } \\
\text { Etiologies }\end{array}$}} \\
\hline & \\
\hline Depression & $0.73 \pm 0.16$ \\
\hline Prolonged hospitalization & $0.71 \pm 0.19$ \\
\hline Polypharmacy & $0.67 \pm 0.22$ \\
\hline Prolonged catabolic illness & $0.67 \pm 0.21$ \\
\hline Use of modified therapeutic diets ${ }^{\mathrm{C}}$ & $0.54 \pm 0.23$ \\
\hline Trauma & $0.50 \pm 0.21$ \\
\hline Etiology total DCV score $^{\mathrm{d}}$ & $0.63 \pm 0.08$ \\
\hline \multicolumn{2}{|l|}{ Nonrelevant characteristics } \\
\hline Malabsorption & $0.49 \pm 0.22$ \\
\hline Disordered eating & $0.46 \pm 0.25$ \\
\hline Inability to obtain preferred foods ${ }^{\mathrm{C}}$ & $0.44 \pm 0.20$ \\
\hline Lack of or limited access to food & $0.42 \pm 0.26$ \\
\hline \multicolumn{2}{|l|}{ Major characteristics } \\
\hline Weight loss of $\geq 5 \%$ within 30 days, $\geq 7.5 \%$ in 90 days, or $\geq 10 \%$ in 180 days & $0.91 \pm 0.17$ \\
\hline Poor intake or appetite (consumes $<75 \%$ offered) & $0.91 \pm 0.17$ \\
\hline Conditions associated with a diagnosis or treatment of some types of cancer or metastatic disease & $0.88 \pm 0.18$ \\
\hline Conditions associated with a diagnosis or treatment of dysphagia & $0.85 \pm 0.18$ \\
\hline Change in mental status or function (eg, depression) & $0.82 \pm 0.21$ \\
\hline \multirow{2}{*}{\multicolumn{2}{|c|}{$\begin{array}{l}\text { Cancer chemotherapy } \\
\text { Minor characteristics }\end{array}$}} \\
\hline & \\
\hline Conditions associated with a diagnosis or treatment of gastrointestinal disease $\mathrm{C}^{\mathrm{C}}$ & $0.79 \pm 0.17$ \\
\hline Loss of muscle & $0.76 \pm 0.21$ \\
\hline Change in eating habits & $0.76 \pm 0.20$ \\
\hline Early satiety & $0.76 \pm 0.22$ \\
\hline Conditions associated with a diagnosis or treatment of chronic obstructive pulmonary disease & $0.75 \pm 0.21$ \\
\hline Conditions associated with a diagnosis or treatment of infection & $0.73 \pm 0.22$ \\
\hline Change in way clothes fit & $0.73 \pm 0.25$ \\
\hline Decreased sense of vision & $0.56 \pm 0.22$ \\
\hline Loss of centrally distributed fat ${ }^{\mathrm{C}, \mathrm{e}}$ & $0.55 \pm 0.26$ \\
\hline Decreased sense of smell & $0.54 \pm 0.26$ \\
\hline Conditions associated with a diagnosis or treatment of AIDS/HIV $\mathrm{e}$ & $0.54 \pm 0.39$ \\
\hline Conditions associated with a diagnosis or treatment of burns & $0.52 \pm 0.39$ \\
\hline Normal or usual estimated intake in face of illness & $0.50 \pm 0.30$ \\
\hline Conditions associated with a djagnosis or treatment of substance abuse & $0.50 \pm 0.28$ \\
\hline Signs/symptoms total DCV score ${ }^{d}$ & $0.69 \pm 0.12$ \\
\hline \multicolumn{2}{|l|}{ Nonrelevant characteristics } \\
\hline Increased respiratory rate & $0.49 \pm 0.25$ \\
\hline Fever $\left(>98.6^{\circ} \mathrm{F}\right)$ & $0.44 \pm 0.24$ \\
\hline Decreased sense of hearing & $0.41 \pm 0.26$ \\
\hline Decrease in waist-to-hip ratio ${ }^{e}$ & $0.35 \pm 0.26$ \\
\hline Increased heart rate $\mathrm{e}^{\mathrm{T}}$ & $0.33 \pm 0.21$ \\
\hline
\end{tabular}

a. Weighted mean score: $\geq 0.80$ = major characteristic, 0.50 to $0.79=$ minor characteristic, $\leq 0.49=$ nonrelevant.

b. International Dietetics and Nutrition Terminology (IDNT) Reference Manual. Chicago, IL: American Dietetic Association; 2009.

c. Items added from literature review.

d. Mean score of validated major/minor characteristics.

e. Rated as "do not know if characteristic" by 15\% or more of Board Certified Specialists in Gerontological Nutrition.

component of the term. Older adults with cognitive impairment have increased risk of unintended weight loss (54) and adverse outcomes $(19,54-56)$. Poor oral health is a contributing factor in the development of involuntary weight loss in the frail elderly population wearing ill-fitting dentures or edentulous (53) and leads to use of texture-modified diets, a validated etiology for involuntary weight loss by the CSGs.

Three assessment categories within the signs and symptoms component were rated incomplete. CSGs reported missing language in the biochemical data, medical tests, and procedures category. Depressed prealbu- 
min $(22 \%)$ and depressed albumin $(16 \%)$ were the most frequent recommended signs and symptoms. The use of these indicators for measuring nutritional status or response to nutrition interventions is inconclusive. Their presence in elderly people who have involuntary weight loss correlates with other coexisting medical conditions, including inflammation and severe illness, known to alter these biochemical parameters (57). Recommended language for the nutrition-focused physical findings category were poor dentition (oral cavity changes, missing teeth, poor fitting dentures, chewing difficulty) $(30 \%)$ and impaired skin integrity (skin breakdown, ulcers, and wounds) $(11 \%)$. Within the client history category, $8 \%$ of the CSGs identified cognitive impairment as needed language.

The signs and symptoms (Table 1) were judged clear and understood by 79\% of the CSGs. The signs and symptoms marked "do not know if characteristic" by $\geq 15 \%$ of the CSGs were items with low DCV scores when rated by the remaining RDs. These scores suggest that, in addition to not being relevant to the diagnosis, the signs and symptoms may not be available or observed when assessing older adults in health care settings.

A strength of this study was the use of experts in gerontological nutrition with experience in involuntary weight loss, the majority of whom practiced in longterm care in all regions of the United States. The study's findings limit the validity of the diagnostic term to a patient population of older adults who reside in extended care facilities. It is expected that other etiologies and signs and symptoms for the diagnosis will be present in other age groups and care settings. For example, the etiologies of depression or high levels of emotional stress validated in the older institutionalized patient would not be prevalent in the younger patient. Lack of or limited access to food, an etiology not validated in this study because of the offering of food and fluids on a consistent basis, may be present in pediatric populations or individuals residing in the community. Axis within nutrition diagnostic terms based on level of care and patient classification, similar to nursing nomenclature, may evolve as research development continues through validation studies.

Future research is needed to continue refinement of the term for use in the older adult. The language additions, recommended by $\geq 8 \%$ of the RDs, need validation by CSGs to derive the major and minor characteristics that are tested in the next clinical phase of validation research. A Clinical Diagnosis Validation Model (27) is used to measure inter-rater independent agreement between RDs of observed presence of the etiologies and signs and symptoms within patients who have the confirmed diagnosis. This model uses the same scoring system of the Diagnostic Content Validity Model.

\section{Conclusions}

The NCP/SL was developed to provide a model for quality care and outcomes management. Validation confirms that the SL is accurate and meaningful to practice. This study validated the content of the definition and more than two thirds of the etiologies and signs and symptoms of the IDNT diagnostic term involuntary weight loss within the older adult institutionalized population. CSGs, who commonly provide care for this nutrition problem, were used as experts. The validated major and minor characteristics, including seven items from the literature review, and the recommendations for added language need to be retested using the same process among CSGs before the term is validated in the clinical setting with older adults. Additional research is required to validate the term in other patient populations and settings. Practitioners should continue to use the SL but anticipate refinement of the terms in future revisions of the IDNT as a result of validation research.

Acknowledgments - This article is a contribution of the University of Nebraska Agricultural Research Division and was supported in part through the American Dietetic Association and the Hatch Act.

\section{References}

1. P. Splett and E. F. Meyers, A proposed model for effective nutrition care, J Am Diet Assoc 101 (2001), pp. 357-363.

2. K. Lacey and N. Cross, A problem-based nutrition care model that is diagnostic driven and allows for monitoring and managing outcomes, J Am Diet Assoc 102 (2002), pp. 578-589.

3. K. Lacey and E. Pritchett, Nutrition Care Process and Model: ADA adopts road map to quality care and outcomes management, J Am Diet Assoc 103 (2003), pp. 1061-1072.

4. Writing Group of the Nutrition Care Process/Standardized Language Committee, Nutrition Care Process and Model Part I: The 2008 Update, J Am Diet Assoc 108 (2008), pp. 1113-1117.

5. American Dietetic Association, International Dietetics and Nutrition Terminology (IDNT) Reference Manual (2nd ed.), American Dietetic Association, Chicago, IL (2009).

6. Workgroup to Study and Recommend a Nutrition Dataset for Inclusion in EMRs and PHRs: Electronic medical records and personal health records: A call for the creation and inclusion of a nutrition dataset http:/ / anhi.org/Learning/PDFs/Other/ EMR-PHR_Nutrition_Dataset_Paper(6-29-09).pdf Accessed May 30, 2010.

7. T. Peregrin, Personal and electronic health records: Sharing nutrition information across the health care community, J Am Diet Assoc 109 (2009), pp. 1988-1991.

8. R. J. Fehring, Methods to validate nursing diagnosis, Heart Lung 16 (1987), pp. 625-629.

9. R. J. Fehring, The Fehring model. In: R.M. Carroll-Johnson, Editor, Classification of Nursing Diagnoses: Proceedings of the Tenth Conference, Lippincott, Philadelphia, PA (1994), pp. 55-62.

10. G. G. Whitley, Processes and methodologies for research validation of nursing diagnoses, Nurs Diagn 10 (1999), pp. 5-14.

11. E. V. Carmona and M. H. B. M. Lopes, Content validation of parental role conflict in the neonatal intensive care unit, In J Nurs Terminol Classif 17 (2006), pp. 3-9.

12. A. S. Melo, E. C. Carvalho and N. T. R. Pela, Proposed revisions for the nursing diagnoses sexual dysfunction and ineffective sexuality patterns, In J Nurs Terminol Classif 18 (2007), pp. 150-155.

13. E. Enrione, Content validation of nutrition diagnosis, Top Clin Nutr 23 (2008), pp. 306-319.

14. P. J. Charney, J. K. O'Sullivan Maillet, R. Touger-Decker, P. Splett, E. Meyers, and S. Haque, Reliability of nutrition diagnostic labels when used by registered dietitians at three levels of practice, J Am Diet Assoc 106 (2006), p. A12.

15. Council for Nutritional Clinical Strategies in Long-Term Care, Anorexia in the elderly: An update, Ann Long-Term Care 9 (suppl) (2001), pp. 1-7. 
16. US Department of Health and Human Services, Health Care Financing Administration, State Operations Manual: Appendix P - Survey Protocol for Long-Term Care Facilities - Part 1: Centers for Medicare and Medicaid Services http:// cms.hhs. gov/manuals/Downloads/som107ap_pp_guidelines_ltcf.pdf Accessed May 30, 2010.

17. Centers for Medicare and Medicaid Services, Nursing Home Quality Initiatives http://www.cms.gov/NursingHomeQualityInits/10_NHQIQualityMeasures.asp\#TopOfPage Accessed May 30, 2010.

18. US Department of Health and Human Services, Health Care Financing Administration, Nursing Home Compare http:// www.medicare.gov/NHCompare Accessed February 4, 2010.

19. American Dietetic Association, Unintended weight loss (UWL) in older adults evidence-based nutrition practice guideline http://www.adaevidencelibrary.com Accessed May 30, 2010.

20. Commission on Dietetic Registration, Board Certified Specialist Gerontological Nutrition Candidate Handbook http:// www.cdrnet.org/certifications/spec/gerontological.htm Accessed May 30, 2010.

21. American Dietetic Association, Position of the American Dietetic Association: Liberalization of the diet prescription improves quality of life for older adults in long-term care, J Am Diet Assoc 105 (2005), pp. 1955-1965.

22. P. L. Splett, L. L. Roth-Yousey, and J. L. Vogelzang, Medical nutrition therapy for the prevention and treatment of unintentional weight loss in residential health care facilities, J Am Diet Assoc 103 (2003), pp. 352-362.

23. H. Payette, V. Boutier, C. Coulombe, and K. Gray-Donald, Benefits of nutritional supplementation in free-living, frail, undernourished elderly people: A prospective randomized community trial, J Am Diet Assoc 102 (2002), pp. 1088-1095.

24. H. H. Keller, A. J. Gibbs, L.,D. Boudreau, R. E. Goy, M. S. Pattillo, and H. M. Brown, Prevention of weight loss in dementia with comprehensive nutritional treatment, J Am Geriatr Soc 51 (2003), pp. 945-951.

25. G. Faxen-Irving, B. Andren-Olsson, A. af Geijerstam, H. Basun, and T. Cederholm, The effect of nutritional intervention in elderly subjects residing in group-living for the demented, Eur J Clin Nutr 56 (2002), pp. 221-227.

26. A. G. Mamhidir, G. Ljunggren, M. Kihlgren, A. Kihlgren, and A. Wimo, Underweight, weight loss and related risk factors among older adults in sheltered housing-A Swedish followup study, J Nutr Health Aging 10 (2006), pp. 255-262.

27. P. K. Ritter-Gooder and N. M. Lewis, Validation of nutrition standardized language-Next steps, J Am Diet Assoc 110 (2010), pp. 832-835.

28. L. M. Hoskins, How to do a validation study. In: M. Rantz and P. Lemone, Editors, Classification of Nursing Diagnoses: Proceedings of the Twelfth Conference, CINAHL, Glendale, CA (1997), pp. 79-86.

29. B. L. Rodgers, Concept analysis: An evolutionary view. In: B. L. Rodgers and K. A. Knafl, Editors, Concept Development in Nursing: Foundations, Techniques, and Applications, W. B. Saunders, Philadelphia, PA (2000), pp. 77-102.

30. L. O. Walker and K. C. Avant, Strategies for Theory Construction in Nursing (3rd ed.), Appleton and Lange, Norwalk, CT (1995).

31. J. Grant and M. Kinney, The need for operational definitions for defining characteristics, Nurs Diagn 2 (1991), pp. 181-185.

32. D. Dillman, Mail and Internet Surveys: The Tailored Design Method (2nd ed.), John Wiley \& Sons, Hoboken, NJ (2007).

33. P. Benner, From Novice to Expert, Addison-Wesley, Menlo Park, CA (1984).

34. T. Merluzzi, R. Rudy, and C. Glass, The information processing paradigm: Implications for clinical science. In: T. Merluzzi, C. Glass, and M. Genest, Editors, Cognitive Assessment, Guilford Press, New York, NY (1981), pp. 77-120.

35. S. M. Sparks and T. Lien-Geischen, Modification of diagnostic content validity model, Nurs Diagn 5 (1994), pp. 31-35.
36. M. Lunney, Accuracy of nursing diagnoses: Concept development, Nurs Diagn 1 (1990), pp. 12-17.

37. G. B. Huffman, Evaluating and treating unintentional weight loss in the elderly, Am Fam Physician 65 (2002), pp. 640-651.

38. B. L. Callen and T. J. Wells, Screening for nutritional risk in community-dwelling old-old, Public Health Nurs 22 (2005), pp. 138-146.

39. J. E. Morly and D. Kraenzle, Causes of weight loss in a community nursing home, J Am Geriatr Soc 42 (1994), pp. 583-585.

40. C. C.-H. Chen, Y.-Y. Bai, G.-H. Huang, and S. T. Tang, Revisiting the concept of malnutrition in older people, J Clin Nurs 16 (2007), pp. 2015-2026.

41. H. Payette, K. Gray-Donald, and R. Cyr, Predictors of dietary intakes in a functionally dependent free-living elderly population, Am J Public Health 85 (1995), pp. 677-683.

42. H. Payette, Nutrition as a determinant of functional autonomy and quality of life in aging: A research program, Can J Physiol Pharmacol 83 (2005), pp. 1061-1070.

43. S. H. Tariq, E. Karcic, D. R. Thomas, K. Thomson, C. Philpot, D. L. Chapel, and J. E. Morley, The use of a no-concentratedsweets diet in the management of type 2 diabetes in nursing homes, J Am Diet Assoc 101 (2001), pp. 1463-1466.

44. L. A. Simons, J. Simons, Y. Friedlander, and J. McCallum, Cholesterol and other lipids predict coronary heart disease and ischaemic stroke in the elderly, but only in those below 70 years, Atherosclerosis 159 (2001), pp. 201-208.

45. I. J. Schatz, K. Masaki, K. Yano, R. Chen, B. L. Rodriguez, and J. D. Curb, Cholesterol and all-cause mortality in elderly people from the Honolulu Heart Program: A cohort study, Lancet 358 (2001), pp. 351-355.

46. L. Wright, D. Cotter, M. Hickson, and G. Frost, Comparison of energy and protein intakes of older people consuming a texture modified diet with a normal hospital diet, J Hum Nutr Diet 18 (2005), pp. 213-219.

47. N. Colodny, Dysphagic independent feeders' justification for noncompliance with recommendations by a speech-language pathologist, Am J Speech Lang Pathol 14 (2005), pp. 61-70.

48. N. Foley, H. Finestone, M.G. Woodbury, R. Teasell, and L. Greene-Finestone, Energy and protein intake of acute stroke patients, J Nutr Health Aging 10 (2006), pp. 171-175.

49. O. Ekberg, S. Hamdy, V. Woisard, A. Wuttge-Hannig, and P. Ortega, Social and psychological burden of dysphagia: Its impact on diagnosis and treatment, Dysphagia 17 (2002), pp. 139-146.

50. B. Lorefalt, A. K. Granerus, and M. Unosson, Avoidance of solid food in weight losing older patients with Parkinson's disease, J Clin Nurs 15 (2006), pp. 1404-1412.

51. H. U. Redman, Involuntary weight loss in the elderly, Clin Geriatr 13 (2005), pp. 37-45.

52. K. M. Chapman and R. A. Nelson, Loss of appetite: Managing unwanted weight loss in the older patient, Geriatrics 49 (1994), pp. 54-59.

53. J. E. Morley, D. R. Thomas, and H. Kamel, Nutritional deficiencies in long-term care: Detection and diagnosis, Ann Longterm Care 6 (1998), pp. 183-191.

54. L. W. Sorbye, M. Schroll, H. Finne Soveri, P. V. Jonsson, E. Topinkova, G. Ljunggren, and R. Bernabel, Unintended weight loss in the elderly living at home: The Aged in Home Care Project, J Nutr Health Aging 12 (2008), pp. 10-16.

55. C. A. Sarkisian and M. S. Lachs, "Failure to thrive" in older adults, Ann Intern Med 124 (1996), pp. 1072-1078.

56. A. R. Fabiny and D. P. Kiel, Assessment and treating weight loss in nursing home patients, Clin Geriatr Med 13 (1997), pp. 737-751.

57. M. P. Fuhrman, P. Charney, and C. M. Mueller, Hepatic proteins and nutrition assessment, J Am Diet Assoc 104 (2004), pp. $1258-1264$. 